\title{
COMPREENDENDO INGLÊS NAS AULAS DO PROJETO DE EXTENSÃO CASAS DE CULTURA NO CAMPUS DA UNIVERSIDADE FEDERAL DE ALAGOAS: LETRAMENTO CRÍTICO COM TEMAS ENFOCANDO ESTEREÓTIPOS E PRECONCEITOS
}

Understanding English in the Lessons of the Outreach Project Casas de Cultura no Campus at Federal University of Alagoas: Critical Literacy with Themes Focusing Stereotypes and Prejudices

Lucas da Silva FRANÇA, Universidade Federal Alagoas ${ }^{1}$ Sérgio IFA, Universidade Federal de Alagoas $^{2}$

RESUMO: O presente artigo objetiva apresentar os resultados de uma pesquisa sobre o desenvolvimento das habilidades de compreensão oral e escrita de alunos do nível básico do curso de inglês oferecido no projeto de extensão Casas de Cultura no Campus (CCC) da Universidade Federal de Alagoas (UFAL). A principal teoria utilizada foi a perspectiva do Letramento Crítico (JANKS, 2013, 2014; LUKE e FREEBODY, 1999; MCLAUGHLIN e DEVOOGD, 2004). A metodologia qualitativa desenvolvida foi a pesquisa-ação (BURNS, 2010; TRIPP, 2005). Os resultados apontam um desenvolvimento significativo da compreensão oral e escrita dos alunos por meio das aulas e atividades temáticas, além do desenvolvimento da consciência crítica, provocado a partir da criação de espaços e oportunidades para que os alunos pudessem se colocar, em língua inglesa, sobre as questões envolvendo estereótipos e preconceitos. Os dados revelam a importância e a possibilidade da articulação entre a perspectiva do letramento crítico e o processo de ensino-aprendizagem de inglês como língua estrangeira.

PALAVRAS-CHAVE: Letramento Crítico; Estereótipos e Preconceitos; Compreensão Oral e Escrita; Língua Inglesa; Projeto de Extensão.

ABSTRACT: This article aims to present the results of a research on the development of students' listening and reading skills in an English course offered by an outreach project called Casas de Cultura no Campus (CCC) at the Federal University of Alagoas (UFAL). The main theory used in the research was the Critical Literacy perspective (JANKS, 2013, 2014, LUKE and FREEBODY, 1999, MCLAUGHLIN and DEVOOGD, 2004). The qualitative methodology we developed was action-research (BURNS, 2010; TRIPP, 2005). The results indicate an expressive development of students' oral and written comprehension through thematic classes and activities, as well as the development of critical awareness, created by promoting spaces and opportunities for students to express themselves in issues dealing with stereotypes and prejudices through the English language. The data reveal the importance and possibility of the articulation between the critical literacy perspective and the English as a foreign language teaching-learning process.

KEY-WORDS: Critical Literacy; Stereotypes and Prejudices; Listening and Reading Skills; English Language; Outreach Project.

\section{INTRODUÇÃO}

Ensinar e/ou aprender uma língua estrangeira (LE) compreende uma tarefa complexa

\footnotetext{
1 Graduado em Letras. Email: lucasfrancalvt@gmail.com

2 Doutor em Linguística Aplicada e professor da UFAL. Email: sergio.letras@gmail.com
} 
REVISTA X, Curitiba, volume 14, n.3,292-304, 2019.

para professores e alunos. Promover o desenvolvimento de uma ou mais habilidades comunicativas (ler, escrever, ouvir, falar) em LE é também um desafio. Queremos, neste artigo, compartilhar nossas experiências e reflexões sobre o ensino-aprendizagem de inglês embasado na perspectiva de ensino do Letramento Crítico (LC) para uma turma de nível básico de inglês do Projeto Casas de Cultura no Campus (CCC), um projeto de extensão da Universidade Federal de Alagoas.

Este artigo é o resultado de uma pesquisa desenvolvida durante o período de agosto de 2016 a julho de 2017 e aprovada no comitê de ética sob o número 34095114.3.0000.5013. Embasamo-nos teoricamente na perspectiva do Letramento Crítico (JANKS, 2013, 2014; LUKE E FREEBODY, 1999; MCLAUGHLIN E DEVOOGD, 2004; IFA e STELLA, 2014) para promover uma formação crítica e cidadã para os alunos. As aulas eram temáticas e promovíamos conversas sobre assuntos que lidavam com questões de estereótipos e preconceitos $^{3}$ de diversos tipos porque queríamos fazer com que os alunos pudessem perceber como as visões sobre essas questões nos afetam direta ou indiretamente e dizem muito sobre como a nossa sociedade as enxerga, as entende e age diante delas.

A seguir, apresentamos a metodologia utilizada, os participantes, a interpretação dos dados, os resultados e as considerações finais.

\section{LETRAMENTO CRÍTICO}

Nessa seção, discorremos sobre a perspectiva do Letramento Crítico (doravante LC) e sobre o ensino-aprendizagem de língua inglesa com foco no desenvolvimento das habilidades de compreensão oral e escrita em língua inglesa. Um dos objetivos em trabalharmos com a perspectiva do LC foi criar a possibilidade de problematizar o significado que as pessoas atribuem às palavras (isto é, as representações materializadas nas palavras) e como elas as usam uma vez que os sentidos que atribuímos estão a todo momento construindo o mundo e as próprias pessoas, em processo constante de (re)construção. Dito de outra forma, ao interpretar um texto ${ }^{4}$, devemos levar em consideração tudo que está no e ao seu redor: quem escreve, para quem, qual a realidade (contexto) do autor, qual a realidade (contexto) de quem lê o texto, quem o texto exclui, quem ele inclui, por exemplo. Nessa direção, concordamos quando Stella e Ifa (2014, p. 169) afirmam que o LC “considera textos como objetos ideológicos, situados, parciais e, por isso, contestáveis", uma vez que os usos que as pessoas fazem dos textos e os significados que atribuem são variáveis.

${ }^{3}$ Discutir sobre a diferença entre o que seria um texto voltado para a discussão de estereótipo ou de preconceito não compreende nenhum dos nossos objetivos aqui, portanto, não trataremos de apresentar a diferença entre eles, pois, durante o trabalho com os temas, trabalhamos de uma forma geral com os dois.

4 A definição de texto aqui abordada baseia-se na definição de Koch e Travaglia (1992) quando dizem que texto vai muito além de apenas composição escrita. Engloba qualquer unidade de sentido que expressa alguma informação como imagens, músicas, por exemplo. 
REVISTA X, Curitiba, volume 14, n.3,292-304, 2019.

Para McLaughlin e Devoogd (2004, p. 55), o papel do professor ao trabalhar com essa perspectiva gira em torno de "ajudar os alunos a tornarem-se criticamente conscientes" com relação a qualquer texto que eles estejam lendo. E, além disso, para eles, o LC não é visto exclusivamente como uma atividade de sala de aula, mas como uma instância usada em todos os contextos de nossas vidas, que vivemos em um mundo no qual "naturalmente participamos em reflexão, ação e transformação" (MCLAUGHLIN e DEVOOGD, 2004, p. 82). Em outras palavras, para esses dois autores, o LC está voltado para uma postura que valoriza o pensar crítico, o refletir e principalmente a mudança de determinada situação por meio de nossas ações. Assim também, Luke e Freebody (1999) sugerem que os estudantes analisem e transformem os textos através de suas ações compreendendo que os textos não são ideologicamente naturais ou neutros, mas representam pontos de vista particulares de quem escreveu, da mesma forma que silenciam outros pontos de vista.

Levemente diferente do que defendem McLaughlin e Devoogd (2004), Janks (2014) argumenta que, na perspectiva do LC, não necessariamente precisamos tomar ações concretas como demonstração (física) para revelar a consciência crítica. Janks (2014) salienta a necessidade de trabalhar com 4 pilares, a saber: o poder (power), o acesso (access), a diversidade (diversity) e a interpretação/reinterpretação (design e redesign). Os pilares são interdependentes.

Em nossas aulas, promovemos discussão e questionamento quando usamos textos (escritos ou orais) em língua inglesa. Tentamos mostrar que textos e discursos não são neutros, posicionando os autores e interlocutores. Procuramos aumentar a conscientização dos alunos sobre as relações de poder existentes, criadas, construídas nos textos e discursos ao questionar, por exemplo, quem está em posição de poder, quem não está, como ele é mantido ali e por quê. Lidar com acesso (access) requer uma atenção a quem tem determinados recursos e quem pode não ter informações disponíveis, por exemplo. Diversidade (diversity) é promover a aceitação e compreensão de que vivemos em uma sociedade múltipla e que os textos devem refletir essa multiplicidade de visões. Interpretar e reinterpretar (design e redesign) é a combinação, interlocução com os outros pilares. Entendemos que problematizar o acesso, mostrar que o mundo é plural e que as pessoas podem enxergar o mundo diferentemente de nós, questionar e determinar quem tem o poder são medidas que alimentam a constante interpretação e reinterpretação do mundo em que vivemos. Ao concordarmos com a autora quando diz que o mundo é construído na e pela linguagem e a mesma molda as formas como compreendemos e atribuímos significado a ele, passamos a considerar fundamental buscarmos formas de questionar e provocar reinterpretações. Em suas palavras, "o que torna o letramento desafiador é a sua criticidade e preocupação com a política de significado: as maneiras pelas quais os significados dominantes são mantidos ou desafiados e mudados" (JANKS, 2016, p. 31). 
REVISTA X, Curitiba, volume 14, n.3,292-304, 2019.

Embasados na perspectiva apresentada por Janks (2014; 2016) para entender as relações língua, texto e discurso, descrevemos, a seguir, nossa compreensão de como podemos trabalhar em sala com as habilidades de compreensão oral e escrita em inglês.

\section{ENSINO-APRENDIZAGEM DAS HABILIDADES DE COMPREENSÃO ESCRITA E ORAL}

Para o ensino-aprendizagem das habilidades de compreensão oral (ouvir) e escrita (ler), adotamos as orientações dos PCN para o ensino fundamental (BRASIL, 1998) e as de Brown (2007) que requerem o trabalho cuidadoso em três etapas: a da fase pré (pre), a da fase leitura ou escuta propriamente dita (while) e a da fase pós (post).

A etapa da pré-leitura ou pré-escuta é aquela em que o professor faz um levantamento do que os alunos já sabem sobre o tema. Para Brown (2007), é nessa etapa que o professor faz com que os alunos se interessem pelo que irão ler ou ouvir. Nessa etapa é possível fazer, por exemplo, uma atividade de vocabulário sobre o assunto do texto. Acreditamos que sempre devemos, ao ensinar uma LE, identificar o conhecimento prévio do aluno, entendido aqui como o ponto de partida. É partindo dele que o trabalho deve ser encaminhado.

A etapa seguinte, a de leitura ou escuta propriamente dita, é aquela em que os alunos têm um contato mais direto com o texto. Eles leem ou escutam para responder as perguntas. São as perguntas que revelam os objetivos traçados para o ensino da referida habilidade, isto é, elas norteiam qual estratégia de leitura ou escuta o professor almeja ensinar, por exemplo, skimming (compreender ideia geral do texto), scanning (identificar ideias especificas no texto), guessing by the context (entender sobre o que o texto fala apenas por informações extras no texto), dentre outras. Na etapa pós-leitura ou pós-escuta, uma possibilidade de atividade é aquela em que, por exemplo, podemos discutir o tema principal da aula e/ou podemos trazer atividades com outra habilidade comunicativa, promovendo assim uma integração entre as habilidades. $\mathrm{O}$ trabalho com a perspectiva do LC nesta investigação reflete o nosso interesse e preocupação em interligar o desenvolvimento das habilidades de compreensão oral e escrita bem como o o desenvolvimento crítico dos alunos.

Por fim, em todas as etapas vistas acima poderíamos trabalhar com a perspectiva do $\mathrm{LC}^{5}$. Entendemos que a promoção da criticidade não acontece em uma etapa específica, mas em qualquer uma das etapas, isto é, cabe a cada professor abrir espaços para questionamentos e

\footnotetext{
${ }^{5}$ Entendemos que há a possibilidade de o professor fazer com que o aluno possa ampliar sua visão inicial sobre o conteúdo que está sendo trabalhado na aula. Ao se trabalhar um determinado texto (escrito ou oral), é possível fazer questões que seguem a perspectiva do LC tanto na etapa pré como na etapa durante. Além das questões já apresentadas pela literatura da área, sugerimos fazer algumas questões: a quem esse discurso/essa fala privilegia? Quem esse discurso não faz referência nessa situação? Por que a pessoa que disse isso pensa da forma que pensa? Escolha um grupo de pessoas não mencionadas nesse texto, o que eles poderiam pensar a respeito? Essas e outras perguntas ficam a critério do professor em identificar qual o momento mais propício para fazê-las.
} 
REVISTA X, Curitiba, volume 14, n.3,292-304, 2019.

pluralizar as visões quando perceber que alunos apresentam opiniões preconceituosas ${ }^{6}$ e do senso comum, informações equivocadas, por exemplo. Optamos, no entanto, nesta investigação, enfocar o trabalho com a criticidade de forma mais explícita e consciente na fase pós-leitura e da pós-escuta porque os alunos foram expostos a mais de uma visão sobre estereótipos e preconceitos nas etapas anteriores por meio dos textos trabalhados.

\section{METODOLOGIA}

Nesta seção, descrevemos os objetivos da pesquisa; a pesquisa-ação como a metodologia escolhida para realização da investigação; as turmas, os participantes; os instrumentos utilizados para geração de dados e os temas relacionados ao foco da pesquisa.

O objetivo da pesquisa foi compreender se o uso de temas e de embasar as aulas de inglês na perspectiva do LC contribuiriam para o desenvolvimento das habilidades de compreensão oral e escrita de alunos do nível básico de língua inglesa no projeto de extensão bem como a formação crítica e cidadã dos alunos. $\mathrm{O}$ foco das aulas foi o de abrir espaços para o desenvolvimento das habilidades linguísticas e para a formação crítica e cidadã dos alunos, através da discussão de temas que lidam com questões de estereótipos e preconceitos de diversas formas porque afetam direta ou indiretamente como a nossa sociedade enxerga, entende e age diante de situações que se evidenciam tais questões.

Para responder ao desafio que nos propusemos a encarar com a pesquisa, a metodologia qualitativa que melhor atendeu ao objetivo foi a pesquisa-ação (BURNS, 2010; TRIPP 2005) que é definida por Burns (2010) como uma investigação que parte da inquietação do pesquisador em identificar um problema ou alguma situação que ele acha que poderia melhorar dentro do ambiente onde ele atua, e em seguida planeja e implementa uma ação naquele ambiente. Neste caso, tal pesquisador tem, assim, um papel de professor-pesquisador e, consequentemente também de um participante da pesquisa. Tal papel pode ser caracterizado como o papel de promotor da aprendizagem, pois, a pesquisa-ação é vista como "participativa na medida em que inclui todos os que, de um modo ou outro, estão envolvidos nela e é colaborativa em seu modo de trabalhar" (TRIPP, p. 448. 2005). Assim como Burns (2010), Tripp (2005) também trabalha com

${ }^{6}$ A definição que adotamos aqui para opiniões preconceituosas gira em torno da expressão de perspectivas que revelam a falta de respeito para com o próximo; demonstram a intolerância e/ou o ódio para grupos menos privilegiados. 
REVISTA X, Curitiba, volume 14, n.3,292-304, 2019.

pesquisa-ação e para a construção do panorama referido acima, tomaremos como base aqui suas definições sobre como tal forma de fazer pesquisa pode se dar.

A pesquisa-ação, para Tripp (2005, p. 446), é vista como uma forma de investigação-ação que se utiliza de técnicas de pesquisa consagradas para orientar a ação que se decide tomar, melhorando assim a prática do pesquisador, pois, a questão aqui é a de que é necessária a ação do pesquisador tanto no ambiente de atuação dele quanto na própria pesquisa, pois, assim como afirma o autor, "a pesquisa-ação requer ação tanto nas áreas da prática quanto da pesquisa, de modo que, em maior ou menor medida, terá características tanto da prática rotineira quanto da pesquisa científica" (p. 447). O processo de pesquisa-ação pode ser esclarecido pelo diagrama ${ }^{7}$ (figura 1) abordado e discutido por Tripp (2005) que o denominou de diagrama da "representação das quatro fases do ciclo básico da investigação-ação".

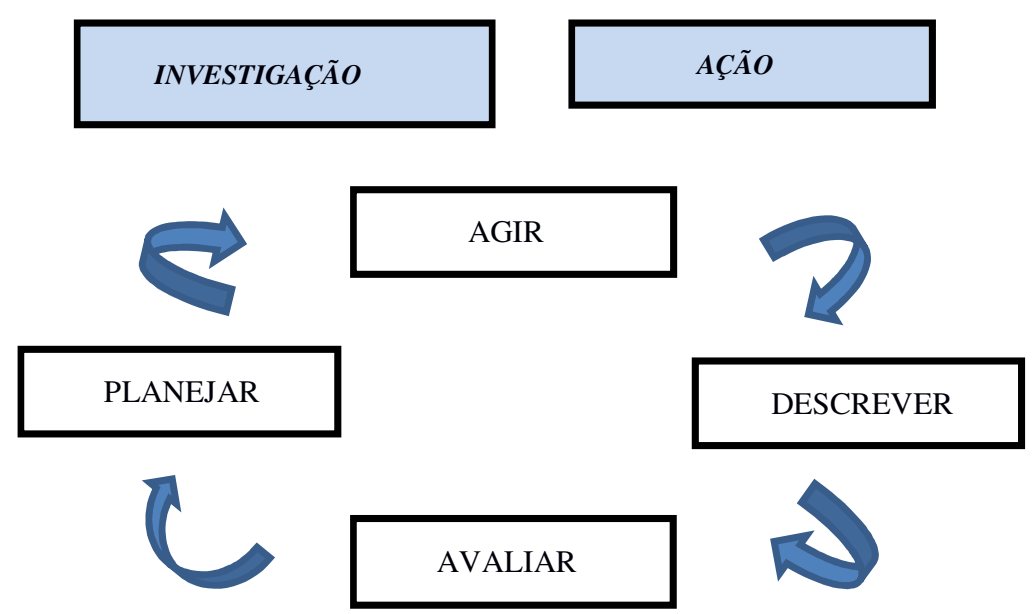

Fig. 1 - adaptação do diagrama das fases da pesquisa-ação de David Tripp, p.446, 2005

Tripp (2005) destaca quatro fases (planejar, agir, descrever e avaliar) que devem ser compreendidas e constituídas como um continuum, pois, os participantes aqui determinam o momento de parar, sempre havendo assim a possibilidade de recomeçar o ciclo. Salientamos que organizamos a pesquisa para que as quatro fases pudessem ser identificadas para nosso crescimento como pesquisadores e para o desenvolvimento da criticidade e das duas habilidades linguísticas enfocadas neste estudo. Identificávamos o que nos inquietava para que, então, pudéssemos pensar em ações e, em função disso, agíamos nas situações para que fossem provocadas melhoras ou modificações.

${ }^{7} \mathrm{O}$ digrama utilizado aqui apresenta algumas modificações do design original do diagrama para maior facilitação da compreensão. 
REVISTA X, Curitiba, volume 14, n.3,292-304, 2019.

Coletamos os dados em duas turmas de nível básico do projeto Casas de Cultura no Campus ${ }^{8}$ : a primeira turma foi composta por 30 alunos (de diversos cursos de graduação da universidade), onde o trabalho se deu especificamente durante os meses de julho a outubro de 2016; e a segunda turma, com 33 alunos (de diversos cursos de graduação da universidade) foi trabalhada durante os meses de janeiro a abril de 2017. Durante o trabalho com a primeira turma foram produzidos 20 planos de aula e 20 diários reflexivos, além de um grande número de atividades e comentários dos alunos nas redes sociais (Facebook e WhatsApp). Já na segunda turma, o numero exato de planos de aula foi 16, e consequentemente 16 diários reflexivos sobre as aulas, além também de diversas atividades e comentários das/os alunas/os nas redes sociais, como postagens escritas no grupo do Facebook, postagens escritas no grupo do WhatsApp, postagens por via de áudio no grupo do WhatsApp, atividades de escrita como atividade de casa, atividades de escrita feitas em sala e apresentação de seminário. Os temas trabalhados com a primeira turma foram feminismo, direitos da comunidade LGBTQ+, identidade de gênero, igualdade de gênero, racismo, dentre outros temas relacionados a problemas sociais que tinham ligação com o dia-a-dia da vida dos alunos. Já na segunda turma, os temas trabalhados foram feminismo, identidade de gênero, racismo, padrões de beleza estabelecidos pela sociedade, igualdade de gênero, intolerância religiosa $\mathrm{e}$ imigração todos eles trabalhados a partir do interesse dos alunos avaliado por questionário inicial online aplicado em ambas as turmas sobre as expectativas que eles tinham com relação ao curso e sobre os possíveis temas que eles gostariam de trabalhar.

\section{INTERPRETAÇÃO DOS DADOS}

Apresentamos aqui os resultados obtidos a partir da interpretação dos planos de aula e dos diários reflexivos acerca do procedimento das aulas, bem como das atividades e temas trabalhados, juntamente com a discussão teórica da perspectiva do Letramento Crítico (JANKS, 2013, 2014; LUKE E FREEBODY, 1999; MCLAUGHLIN E DEVOOGD, 2004) e das teorias sobre o processo de ensino-aprendizagem de línguas estrangeiras (MCLAUGHLIN E DEVOOGD, 2004; HARMER, 1998), focalizando o desenvolvimento das habilidades de

${ }^{8}$ O Projeto Casas de Cultura no Campus é um projeto que objetiva ensinar línguas (inglesa, espanhola, francesa, Libras e português instrumental) para os alunos da graduação da UFAL e para alunos do ensino médio de escolas públicas que estão no entorno da universidade. Outro objetivo do projeto é propiciar a formação para os alunos dos cursos de Letras durante sua licenciatura. Ao ingressarem no projeto, os alunos são denominados de PFI (professores em formação inicial), recebem uma bolsa pela pró-reitoria de Extensão (ProEX/UFAL) e são responsáveis por uma turma com 30 alunos (em média), com 2 aulas de 100 minutos por semana. Devem também frequentar as 2 reuniões de 100 minutos cada durante a semana. A orientação teórico-didático-metodológica é feita pelo coordenador do curso. 
REVISTA X, Curitiba, volume 14, n.3,292-304, 2019.

compreensão oral e escrita.

Primeiramente, para identificar quais temas ${ }^{9}$ melhor colaboraram com o desenvolvimento da compreensão oral e escrita dos alunos foi preciso partir do interesse deles, pois, acreditamos que quando trabalhamos com algo que os alunos estão interessados eles acabam se empenhando muito mais e, consequentemente, aprendendo. Dentre os temas, os mais votados foram: feminismo, igualdade de gênero e racismo.

Por conta da popularidade do tema feminismo, a participação e o empenho dos alunos, após um trabalho com o texto escrito, registrado na captura de tela (figura 2) de uma das enquetes criadas em uma das redes sociais ${ }^{10}$ (Facebook) em que os alunos postaram suas impressões sobre a leitura do texto sobre tabu da sexualidade feminina.

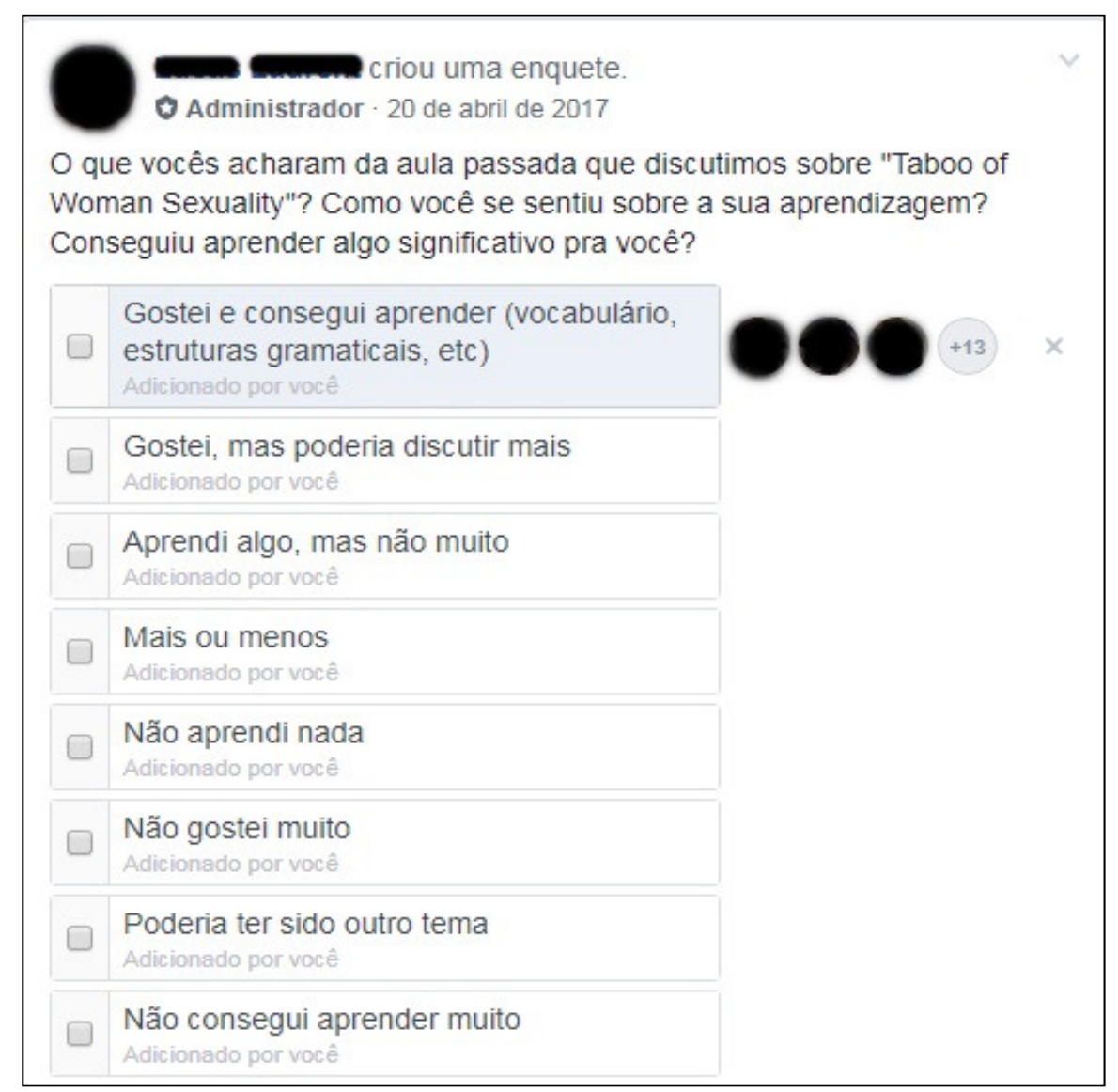

Fig. 2 - Enquete: impressões sobre a leitura do texto sobre o tabu da sexualidade feminina

${ }^{9}$ Salientamos que o foco deste trabalho foi uma pesquisa-ação em que objetivamos provocar uma mudança no processo ensino-aprendizagem da língua inglesa em um curso de extensão. Em vez de trabalhar os temas apresentados pelo livro didático, convidamos os alunos a elencar por quais temas do cotidiano eles se interessam e gostam de conversar. Dessa forma, não queremos dizer que os temas são suficientes para o sucesso do processo. No entanto, queremos enfatizar que, pela nossa experiência, partindo dos temas, o desenvolvimento das habilidades foi desencadeado de forma mais significativa.

${ }^{10}$ As redes sociais (Facebook e Whatsapp) apresentaram um papel importante para a construção dessa pesquisa, porque, foi através delas que as alunas e os alunos interagiam, tanto expondo feedbacks sobre as aulas e também tanto com relação ao seu próprio aprendizado, quanto com relação a facilitação de acesso às atividades que as redes sociais propiciaram. 
REVISTA X, Curitiba, volume 14, n.3,292-304, 2019.

Podemos observar também o desenvolvimento da aprendizagem dos alunos em língua inglesa como também da consciência crítica por meio da captura de tela (figura 3) de uma das postagens no Facebook. Os alunos deveriam expressar sua opinião no grupo após fazerem atividades de compreensão oral de um vídeo ${ }^{11}$ que discutia sobre igualdade de gênero no mercado de trabalho. Podemos dizer que foi surpreendente o desenvolvimento dos alunos, porque eram alunos de nível básico. A cada atividade, um desafio para que pudessem se expressar. Os dados que trazemos revelam que os alunos, por meio da interação, conseguiram conversar, dialogar e expressar suas ideias de forma contextualizada e com um bom desempenho linguístico-discursivo. Tal resultado não é comum de ser encontrado em cursos básicos de língua inglesa. Os pequenos erros de gramática de forma alguma impediram a compreensão e a comunicação. Essa experiência foi muito significativa porque revelou que ensinar e aprender língua inglesa vai muito além de trabalhar com aspectos gramaticais exclusivamente. $\mathrm{O}$ foco deve ser na expressão das ideias e na comunicação.

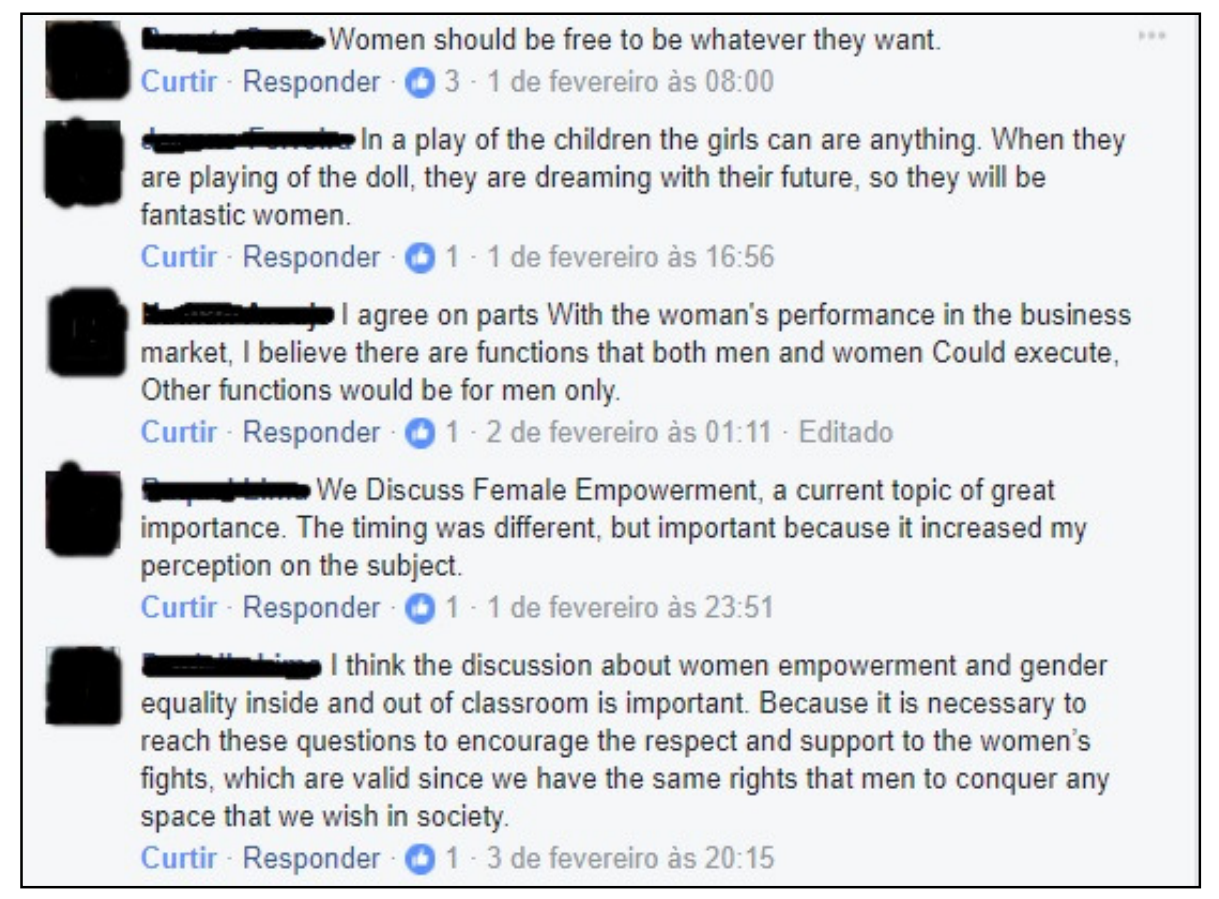

Fig. 1 - Opinião dos estudantes sobre um vídeo que discutia igualdade de gênero no mercado de trabalho.

A interpretação do conteúdo das capturas de tela revelou o quão significativo o tema foi para o desenvolvimento das habilidades linguísticas e do desenvolvimento crítico-cidadão porque eles conseguiram se expressar e trocar ideias. Tal importância do trabalho realizado pode

${ }^{11} \mathrm{O}$ vídeo é uma campanha de uma marca de bonecos que mostra crianças do gênero feminino em diversas profissões. Durante a aula, por meio de uma das mais variadas e possíveis interpretações do texto, entendemos a problemática apresentada como uma crítica à questão de desigualdade de gênero no mercado de trabalho. Link para o vídeo: https://www.youtube.com/watch?v=11 vnsqbnAkk 
ser corroborada, por exemplo, pelos comentários, no final do curso, da aluna Letícia $^{12}$ : "Acredito que eu tenha aprendido grande parte do vocabulário trabalhado." - podendo ser constatado em outra postagem da mesma aluna sobre uma atividade relacionada ao desenvolvimento da compreensão oral, na qual ela faz uso do vocabulário que ela disse ter aprendido (ver figura 4) - "E também a interpretação dos textos associados às discussões sobre os diversos temas me ajudou a usar as palavras-chave para entender o contexto do assunto tratado".

Magna, perguntada sobre como ela havia percebido seu desenvolvimento em língua inglesa, afirma: "Eu acho que, eu percebi, tipo, quando vejo uma série, ou vejo alguma notícia, e consigo ver termos que aprendi durante as aulas, os debates.".

Thathiana, a terceira participante, afirma que: "eu cheguei à conclusão que consegui aprender com os temas abordados em sala porque fazer uma ligação entre temas que são polêmicos e principalmente do nosso cotidiano com a língua inglesa permitiu uma facilidade em assimilar os conteúdos.”.

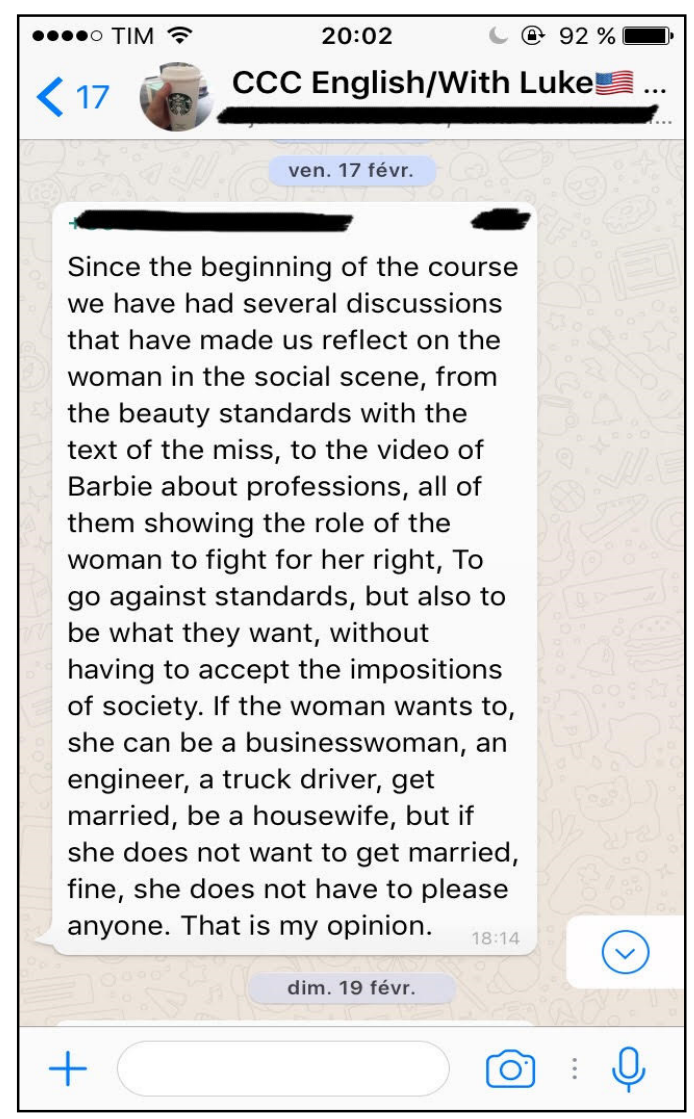

Fig. 2 - Produção escrita da aluna Letícia.

12 Utilizamos aqui quatro nomes fictícios - Letícia, Magna, Thathiana e Soni - para preservar as identificações das participantes. Realçamos que todas as participantes assinaram o TCLE (Termo de Consentimento Livre e Esclarecido) submetido ao e aprovado pelo Comitê de Ética da Universidade. 
REVISTA X, Curitiba, volume 14, n.3,292-304, 2019.

Interpretamos cada comentário como revelador de uma faceta do trabalho de um professor de língua estrangeira como o inglês no contexto brasileiro: Letícia refere-se exclusivamente às atividades trabalhadas em sala como as atividades de leitura, de vocabulário e as discussões para promoção da criticidade; Magna, por sua vez, revela outras características do trabalho que os alunos ajudaram a construir - para ela, o aprendizado é revelado no exterior, isto é, no mundo exterior à sala de aula porque ela conseguiu usar o conhecimento construído em sala na sua vida cotidiana; já Thathiana traz a interconexão que ela faz entre os temas que foram trabalhados em sala com "os temas" que circundam a realidade dela, provocando assim a facilidade na aprendizagem por apresentarem-se significativos a medida que ela pode estabelecer relações entre eles. Em resumo, os comentários das três participantes exemplificam características fundamentais do processo de ensino-aprendizagem porque envolvem as atividades realizadas e o conhecimento produzido em sala de aula e que também pode ser utilizado fora dela. Queremos sublinhar que um aspecto muito importante para nós pesquisadores e professores foi o fato de Thathiana ter mencionado as conexões que ela fez entre o que é construído em sala de aula com o que ela vivenciou no mundo exterior. Provocar conexões facilitou a aprendizagem, isto é, o desenvolvimento das habilidades em foco. Tal afirmação confirma a relevância de trabalhar com temas de interesse (escolhidos pelos alunos) para que eles consigam relacionar criticamente o conteúdo do curso com as experiências cotidianas.

Outra atividade feita com os alunos foi realizada com o tema racismo. Os alunos deveriam relatar, utilizando o vocabulário aprendido em sala, sobre o que havia sido feito após a leitura e a discussão de um texto escrito. Na figura 5 abaixo, destacamos o comentário da aluna Soni porque revela a relação entre língua e sociedade e as múltiplas visões que um texto apresenta e que podem ser discutidas relata por meio do trabalho com a perspectiva do LC. Na figura 5, a aluna relata que "trabalhamos em sala o preconceito (aqui se referindo a racismo) de diferentes formas". Podemos perceber aí a importância do LC em aulas de línguas, porque possibilita ao aluno enxergar o mundo levando em consideração, caso queira, as diversas visões as quais teve contato e as construídas em sala de aula. Salientamos também que não há apenas um ponto de vista a ser considerado, mas diversos que podemos discutir e analisar. A produção escrita da aluna coroa o trabalho realizado no curso porque propiciou desenvolvimento 
REVISTA X, Curitiba, volume 14, n.3,292-304, 2019.

linguístico-discursivo na habilidade da escrita, na compreensão do texto escrito e ampliação/compreensão de outros pontos de vistas.

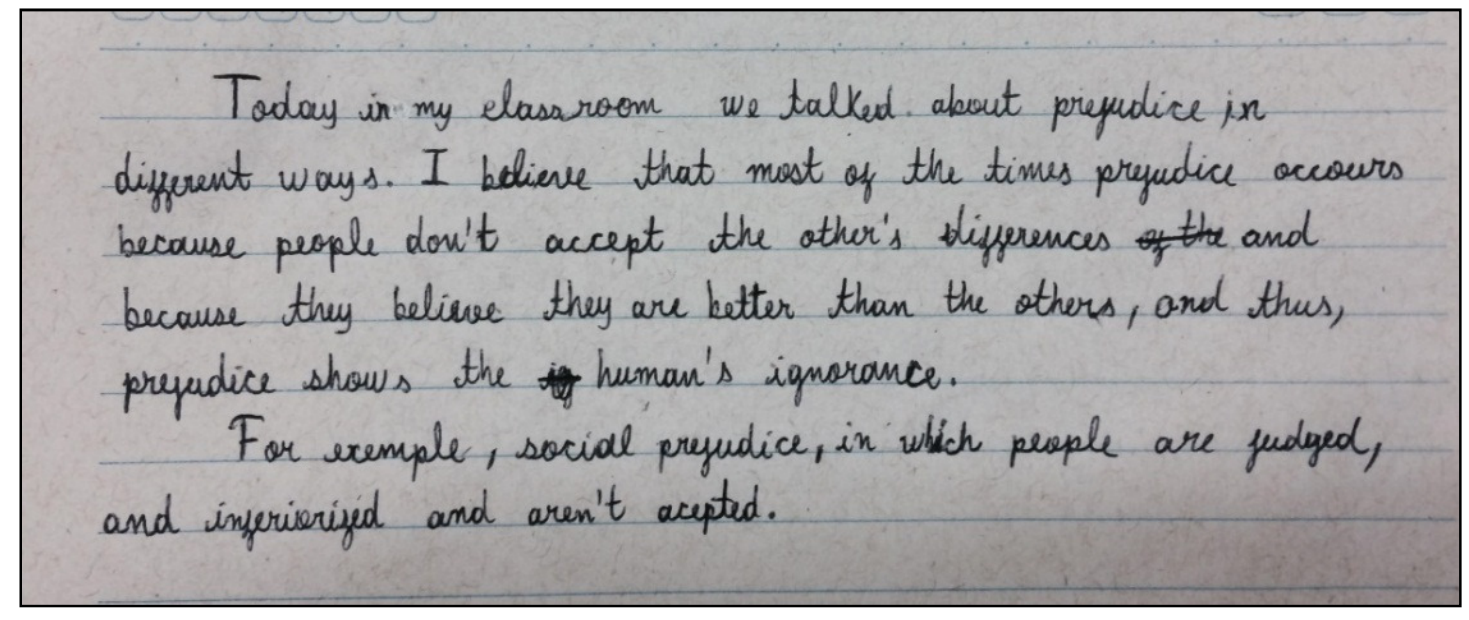

Fig. 3 - Produção escrita da aluna Soni.

\section{CONSIDERAÇÕES FINAIS}

Tomando como base a perspectiva do LC defendida por Janks (2014), muitos alunos desenvolveram uma consciência crítica significativa porque objetivamos oferecer aulas diferentes das aulas tradicionais (voltadas somente para o ensino de gramática), isto é, aulas inovadoras que a maioria dos alunos nunca teve antes. Nessas aulas, propiciamos um ambiente para conversar sobre temas de interesse da maioria dos alunos para construção de sua formação cidadã e de sua consciência crítica. Os alunos puderam não só desenvolver sua formação cidadã/crítica como também seu desenvolvimento das habilidades de compreensão oral e escrita em língua inglesa.

Ter realizado a pesquisa-ação revelou que o trabalho temático foi extremamente importante porque levamos temas para a sala de aula que os alunos escolheram. As atividades planejadas contribuíram para o desenvolvimento das habilidades de compreensão oral e escrita. Dentre as atividades trabalhadas, destacamos as realizadas por meio das redes sociais porque puderam estimular os alunos a escreverem sobre os temas trabalhados em sala.

Isto é, as redes possibilitavam o acesso, durante todo o processo de desenvolvimento das habilidades, às informações de uma forma muito mais rápida. Isso colaborou significativamente para o empenho dos alunos em realizar as atividades propostas e, como era algo diferente e inovador porque saía da realidade de ter apenas atividades realizadas em sala de aula, eles se interessaram muito mais. Os dados interpretados na seção anterior confirmam que os alunos puderam desenvolver as habilidades linguístico-discursivas em língua inglesa. Além disso, foi por meio das redes sociais que os alunos usaram a língua inglesa com propósitos reais e significativos. 
REVISTA X, Curitiba, volume 14, n.3,292-304, 2019.

Para finalizar, tomamos como base o pensamento de Janks (2013), ao dizer que o "Letramento Crítico é destinado a ser transformador" (JANKS, p. 229. 2013), na medida em que acreditamos que essa perspectiva tenha colaborado consideravelmente para os resultados, propiciando, como os alunos disseram, um ambiente que os fez pensar e discutir sobre assuntos que normalmente nunca eram levados e discutidos em salas de aula de línguas estrangeiras.

\section{REFERÊNCIAS}

BRASIL. Parâmetros curriculares nacionais: terceiro e quarto ciclos do ensino fundamental: língua estrangeira / Secretaria de Educação Fundamental. Brasília: MEC/SEF, 1998.

BROWN, D. H. Teaching by principles: an interactive approach to language pedagogy. United States of America: Pearson Longman, 2007.

BURNS, A. Doing action research in English language: a guide for practitioners. New York: Routledge, 2010.

HARMER, J. How to teach english. England: Pearson Education Limited, 1998.

JANKS, H. Critical literacy in teaching and research. University of South Australia: Education Inquiry, 2013.

JANKS, H. Critical literacy in teaching and research.University of South Australia: Education Inquiry, 2013.

JANKS, H. Doing critical literacy: texts and activities for students and teachers. New York: Routledge, 2014.

JANKS, H. Panorama sobre Letramento Crítico. In: JESUS, D. M. e CARBONIERI, D. (Orgs.). Práticas de multiletramentos e letramento crítico: outros sentidos para a sala de aula de linguas. Campinas, SP: Pontes Editores, 2016. p. 21 - 39.

KOCH, I.; TRAVAGLIA, O. Texto e coerência. São Paulo: Cortez, 1992.

LUKE, A.; FREEBODY, P. Further notes on the four resources model. New Jersey, US: Reading Online Magazine, $1999 . \quad$ Disponível em: $<$ http://readingonline.org/research/lukefreebody.html > . Acesso em: 20 Out. 2017

MCLAUGHLIN, M.; DEVOOGD, G. Critical literacy as comprehension: expanding reader response critical literacy helps teachers and students expand their reasoning, seek out multiple perspectives, and become active thinkers. USA: Journal of Adolescent \& Adult Literacy, vol. 48, $2004 . \quad$ Disponível em: $<$ https://www.jstor.org/stable/40012284?seq=1\#page_scan_tab_contents $>$. Acesso em: 15 Out.2017

STELLA, P.; IFA, S. Uma perspectiva letrada para o referencial curricular de línguas estrangeiras em Alagoas: questões e desafios. In: STELLA, P. R.; CAVALCANTI, I.; TAVARES, R.; IFA, S. (orgs.). 2014. Transculturalidade e descolonialidade nos estudos em inglês no Brasil. Maceió, Al: Edufal.

TRIPP, D. Pesquisa-ação: uma introdução metodológica. Educação e Pesquisa, São Paulo, v.31, n 3, 2005. 